\title{
Folia Primatologica
}

Aigueperse, J. 189, 190

Allenet-Le Page, B. 189, 190

Assersohn, C. 226

Aujard, F. 191

Aureli, F. 222

Bacon, A.M. 192

Barbe, S. 193

Bayart, F. 200, 217

Bazile, C. 203

Bénard, P. 193, 198

Berge, C. 206

Bernardé, A. 219

Bertrand, F. 207

Blanquié, J.P. 207, 219

Blois-Heulin, C. 194

Boismon, C. 198

Boller, F. 197, 202, 218

Bonnier, R. 198, 209

Bons, N. 199

Bovet, D. 195

Buchanan-Smith, H.M. 227

Byrne, R.W. 225

Caless, S. 230

Ceska, V. 201

Chauvier, F. 207

Chevalier, G. 193, 198

Colas, S. 195

Contamin, H. 217

Coulibaly, C. 196, 207

Crozier, F. 217

Damerose, E. 208

Demarquay, C. 189,190

De Michelis, S. 215

Dhenain, M. 197, 202, 218

Didier, S. 199

Di Trani, C.M.P. 215

Dunbar, R.I.M. 221

Durand, S. 198

Duyckaerts, C. 197

Elton, S. 230
Filaquier, C. 193

Fleury, M.C. 211

Florence, G. 198, 209

François, C. 220

Gachot-Neveu, H. 210

Gauthier, C.A. 202, 211, 218

Gautier, J.P. 211

Génin, F. 212

Germain, C. 198

Gómez, J.C. 222

Gommery, D. 213

Gourmelon, P. 189, 190

Gouteux, S. 214

Guédot, Ch. 199

Hartinger, J. 196, 207

Hill, K. 226

Hill, R.A. 228

Huyghe, B. 198

Ivantcheva, A. 199

Jahan, P. 219

Jakob, V. 196, 207

Joffe, T.H. 223

Joubert, C. 189,190

Keller, E. 199

Kudo, H. 221

Lagarde, D. 209

Lernould, J.-M. 201, 216

Lici, D. 198

Louguet, O. 200, 217

Magliocca, F. 215

Martin, J. 225

Martinez, B. 211

Michot, J.-L. 197, 202, 218

Moisson, P. 201, 215, 216

Müller, M. 196, 207

Mumumbila, M.V. 210

Nogge, G. 201

Nugent, M. 217
Onéda, S. 198

Perret, M. 197, 212

Petit, O. 202

Pickford, M. 213

Picq, J.-L. 197, 202, 218

Plagnes, D. 209

Plesker, R. 196, 207

Prescott, M.J. 227

Puozzo, C. 193

Rigout, F. 203

Riondet, L. 209

Roger, T. 203, 204, 204

Roullet, D.L.E. 211, 218

Rumpler, Y. 201

Sambrook, T. 229

Sautel, F. 193

Schaffner, C.M. 224

Seguin, Y. 207

Senut, B. 213

Stofleth, Y. 204

Stokes, E.J. 225

Strate, M. 228

Taylor, M. 229

Thibault, B. 204

Thinus-Blanc, C. 214

Thoisy, B. de 200, 217

Tran, D. 209

Van Beers, P. 209

Vauclair, J. 195, 208, 214

Vercauteren Drubbel, R. 211

Verdier-Cellier, C. 205

Verschuere, B. 198

Vinclair, P. 193

Viso, M. 219

Volk, A. 197

Whiten, A. 205, 224, 226

Yelnik, J. 220

\section{KARGER}

๑ 1999 S. Karger AG, Basel

Fax + 41613061234

E-Mail karger@karger.ch

www. karger.com

Accessible online at:

http://BioMedNet.com/karger 